\title{
Integrating exhibit marketing into integrated marketing communications
}

\author{
Dennis A. Pitta, Margit Weisgal and Peter Lynagh \\ Merrick School of Business, University of Baltimore, Baltimore, Maryland, USA
}

\begin{abstract}
Purpose - The purpose of this paper is to explore developments in the field of integrated marketing communication and the changing relevance of its component processes that have implications for marketing managers.

Design/methodology/approach - The paper integrates concepts including a range of recently published (1993-2005) theoretical works, practitioner developments in practice and industry studies.

Findings - The paper provides information and action approaches to marketing communicators that may increase the success of their promotional efforts. In addition, the paper provides a useful perspective in the proper use and applications of event marketing. It outlines the benefits of adopting event-marketing techniques and offers practical suggestions for maximizing their value in the promotion process.

Research limitations/implications - The theoretical concepts that form the foundation of the paper appear to have a significant application to the integrated marketing communications. Some, but not all, have been tested empirically.

Practical implications - This study allows marketing managers to reformulate their marketing communications mix to achieve a more successful promotional process.

Originality/value - This paper describes current trends in event marketing, explores the elements of event marketing and repositions them into an enhanced integrated marketing communications framework. It offers the potential of improving the success of the promotion of products and services in practice, resulting in increasing effectiveness. Moreover, it provides a strategic perspective that is necessary for an effective integrated marketing communications process.
\end{abstract}

Keywords Integrated marketing, Marketing communications, Promotional methods, Trade fairs

Paper type Conceptual paper

An executive summary for managers and executive readers can be found at the end of this article.

\section{Introduction}

Integrated marketing communications (IMC) emphasize the benefits of harnessing synergy across multiple media to build brand equity of products and services. Theoreticians and practitioners have embraced the concept and it is firmly entrenched in marketing. The American Association of Advertising Agencies (Schultz, 1993) defines IMC as follows:

A concept of marketing communications planning that recognizes the added value of a comprehensive plan that evaluates the strategic roles of a variety of communication disciplines - for example, general advertising, direct response, sales promotion, and public relations- and combines these disciplines to provide clarity, consistency, and maximum communications impact.

This definition recognizes the added value aspect of IMC, created by the joint impact of multiple activities in the promotion mix, It does not, however, provide a comprehensive articulation of the variety of promotion mix elements that comprise IMC.

IMC is a powerful tool in reaching target audiences with persuasive messages. Over time, though, academics have

The current issue and full text archive of this journal is available at www.emeraldinsight.com/0736-3761.htm

Journal of Consumer Marketing

23/3 (2006) 156-166

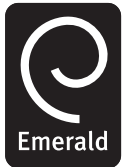

(C) Emerald Group Publishing Limited [ISSN 0736-3761]

[DOI 10.1108/07363760610663312] debated its nature and scope (Gould, 2000). Throughout its lifetime, marketers have been able to select the correct combination of promotion mix elements to be effective in a specific competitive situation. Marketers may choose to employ any combination of advertising, personal selling, word of mouth, publicity, sales promotion or any other tool that gains attention, awareness and creates an image. Moreover, there are variations of the main promotion mix elements to help refine the promotional effort. One of the great strengths of IMC is its flexibility. A finely crafted IMC effort can influence target audiences that would otherwise be unreachable. The most extreme example originates in the USA and deals with influencing federal acquisition decision makers (McCarthy, 2005). Federal government acquisition projects are managed by as many as 50 designated purchasing agents who comprise the "purchasing commission". In the private sector, influencing purchasing agents would be accomplished by personal means. Companies would send sales and public relations personnel to convey the organizational message, often communicated over dinner or a round of golf, so the company could get to know the decision maker and influence the purchase. To combat these tactics, there are very strict US federal government rules that govern interaction with federal purchasing personnel. The rules restrict federal contractors from spending more than $\$ 50$ per person per year in promotional outlays. This effectively prohibits the standard wining and dining that goes on in the private sector and creates a significant obstacle.

How do federal contractors reach the purchasing commission members? They use the flexibility of IMC. Recently, in the Washington, DC area, they have begun buying large amounts of mass advertising space and time. In 
fact, a small selection of radio stations run advertising touting arcane government projects, using government linked jargon that is indecipherable to the ordinary consumer. The idea is to reach, via radio advertising, the 50 or so commission members. The other 40,000 listeners exposed to the campaign hold little value to the contractors. Ordinarily, advertisers would try to avoid wasted exposure and its cost but, in this case, wasting a large amount of exposure is well worth it. Reaching the few decision makers with a $\$ 15,000$ advertising campaign may result in a billion-dollar contract. In perspective, the cost of preparing the proposal itself may run to $\$ 1$ million, so the relatively small cost of the advertising campaign can actually be a bargain.

This example serves to show that IMC, if handled very well, can reflect a unique combination of elements depending on the promotional situation. It also shows that IMC is versatile and effective. That versatility is vital today.

The new millennium ushered in a period of unparalleled consumer choice and unparalleled challenges for marketers. While marketers have long recognized the fracturing of the broadcast entertainment industry, recent events have pushed traditional boundaries well beyond expectations. The widespread availability of cable television systems offering 200-300 channels of entertainment catering to an almost unimaginable variety of tastes has humbled traditional television networks. Similarly, cable news networks have weakened the influence of network news operations.

The challenge is worse than the threat posed just 15 years ago by television remote controls or the videocassette recorder. Then, advertisers worried about users "zapping" commercials when watching live television. Zapping is the act of changing the channel to avoid a commercial. In contrast, "zipping" is the act of fast-forwarding the tape in a VCR to accomplish the same thing with recorded content. Marketers are attempting to counterattack with applications of technology. One example is Vintage Television programming. The idea is to show classic television reruns from the Golden Age of television (1950-1970) in which the programming is free, but technology prevents consumers from avoiding the modern commercials that pay for the broadcast. Other twenty-first century challenges like the increasing popularity of $\mathrm{TiVo}^{\circledR}$, the television on demand combination of hardware and software, make it even easier to avoid commercial broadcast messages.

Other developments affect the standard media used for promotion. For example, the telephone, the tool of telemarketers, is far less effective as a promotional tool than it once was. Technology is one factor that hurts telemarketing. The widespread availability of telephone Caller ID allows customers to screen calls and ignore those that come from suspect numbers. There are other factors at work. Responding to consumer complaints, governments have instituted consumer safeguards such as the "Do not call" lists. There is a similar version to halt unwanted credit card offers. Consumers who subscribe to the government maintained lists could insulate themselves from unwanted telephone solicitations. There are some loopholes that telemarketers can exploit to reach even people identified as "do not call" contacts. After learning the details of the law, telemarketers took steps to reconnect with their target audience by creating what is, in effect, a promotional campaign. For example, companies have offered to send a free gift with no obligation to the recipient; accepting such gifts, unfortunately, is tantamount to having a preexisting relationship with the firm. Thus consumers who accept such offers would make themselves legitimate targets of telemarketing. Despite these techniques, telemarketers are less effective than they used to be.

So, with less effective tools available to reach consumers, some marketers are increasing their advertising with the unintentional effect of boosting clutter. Past research cited 2,000 as the average number of advertising impressions beamed to the average consumer daily. Recent data boosts that estimate to be upwards of 3,000 (Shenk, 1997). In reality the number of exposures is probably much lower. Nevertheless, the amount of advertising clutter results in substantial wasted advertising exposure and the reduction of advertising effectiveness.

The result is that marketers no longer have reliable and effective ways to reach mass markets to get their message out. The situation may not be catastrophic; they can still hit niches. The 200 to 300 cable TV channels available in many locations provide narrowcasting opportunities that have the potential to reach very specific audiences interested in very specific topics. Astute advertisers hope to reap the benefits of specificity. Audiences interested not only in sports, but also in specific sports, like tennis, soccer, Australian rules football and others, have channels designed for their interests. However, viewers' commercial avoidance behavior will diminish the specificity benefits.

As marketers seek ways to get consumers' attention, outside events have been shown to be effective. Consumers at events are immersed in the moment and actively participating in the experience. Events are quite different than any encounter with broadcast media in a variety of ways. For example, the event may be interactive, as with sporting events. Even at baseball games, one of the more sedate spectator sports, the crowd can cheer, complain or catch a foul ball.

The interactivity in such events usually means that consumers experience heightened involvement in the situation. They may attend to cues or advertising stimuli at the event that are programmed by marketers. On the other hand, watching a baseball game is still really just a spectator sport. Attendees may be more involved than they are when watching television but they are not players. On a continuum ranging from no involvement or awareness to high involvement and active participation, a sporting event ranks toward the high involvement end. Involvement is critical to successful marketing communications. The reason that personal selling and word of mouth are more effective than advertising and publicity is thought to be due to their higher personal involvement level.

IMC's selective use of elements and flexibility allow promotion managers a useful range of applications. As the effects of the environmental factors noted above have grown, marketers have exploited IMC's flexibility to reach their target audiences. Like gourmet chefs, they have adjusted their promotional recipes to attract consumers. As a result, marketers have rediscovered exhibit marketing in the last few years.

\section{Historical treatment of exhibit marketing}

Exhibit marketing is a rich and versatile promotional practice that spawns new applications and has the power to adapt to changing situations. For example, a relatively new exhibit 
marketing form has "popped up". Called a "pop-up store" it refers to a temporary retail establishment that might last a month or two and often used for seasonal products and services. Since they are unusual and novel applications, popup stores generate considerable publicity and promotion value. They have sprung up in major US cities, malls and even airports and include both mainstream retailers and firms with new products to introduce. Pop-ups and other buzz marketing techniques seek to "keep the edge". In other words, astute marketers are in a race to attract consumers' interest and attention, one which involves developing something new before the latest technique gets stale and loses effectiveness. What is clear is that the industry realizes that conventional advertising is much less effective. In fact, 2004 was described as the year that the traditional 60 -second advertising spot died. The comment is an exaggeration, but reflects the new direction. There are predictions that the new type of marketing budget will feature more event and exhibit marketing.

Exhibit and event marketing share some characteristics. First, they are events with some commercial purpose because they are experiences that require attendees to act within the event situation. If the event is a business to business (B2B) trade show, both parties come together for a related purpose: to promote or experience a group of vertical products and services. The commercial purpose of the show is overt and the players participate actively. Companies may take orders for their products and have tangible sales results. The Consumer Electronics Show, with over 2,500 exhibiting firms, is an example of such a B2B exhibit marketing event.

Similarly, even if the event is aimed at consumers as with craft shows, home and garden shows, boat shows or the like, there is an overt commercial purpose. That purpose is to promote the products and services featured. It is less likely that the show will generate commercial sales but, depending on the event, they happen. If on the other hand, the event is a "festival," or a rock and roll concert, the commercial purpose is muted and the sponsor gains less commercial benefit. Typically, the desired result may be awareness and image creation, but not necessarily sales.

While both forms of experiential marketing have grown in importance, we will focus on exhibit marketing, specifically trade shows. In 1995, trade shows accounted for between 1620 percent of a business's marketing budget (Chapman, 1995). A study in 2004 conducted among 700 marketing decision makers in the automotive, high-tech, financial and health care industries showed that budgets had grown to above the 20 percent level (Barker, 2005). In dollar terms, that figure approximates an incredible $\$ 166$ billion (Spethmann, 2005). For many small businesses with limited budgets, trade shows and personal selling are the only promotion mix elements available. Despite its clear importance, exhibit marketing is essentially ignored in the recent academic literature. During the 1970s and 1980s the academic literature recognized the importance of exhibit marketing and devoted considerable attention to its theory and practice. Since then, there has been very little academic interest: there are few academic references and little academic understanding of the costs, benefits and operation of trade shows. Moreover, few college curricula cover the topic in appreciable detail. As a result, universities do not prepare their graduates to understand or to manage exhibit marketing. In fact, many marketing and promotion managers know little about trade shows and how to exploit their vast potential. That lack of knowledge can lead to waste and failure. What they do learn is experiential and that experience is untutored and usually accidental. As a result the lessons they learn are incomplete and, even worse, may be totally incorrect (Weisgal, 1997).

Exhibit marketing plays an important role in the IMC mix for many companies. A trade show can be an important part of a firm's overall program if properly executed (Kerin and Cron, 1987). It has been estimated that more than 9,000 industrial, scientific, and medical expositions take place in the USA every year. In addition, many firms exhibit at more than one show. It is important that those responsible for building, executing and maintaining an effective, efficient IMC program consider the contribution that exhibit marketing can make.

In the past, trade shows were grouped loosely with sales promotion, the catchall category that included all that was not advertising, personal selling, publicity or word of mouth. Before heightened global competition and ever tightening promotional budgets, employee trade show participation was often treated as a reward for successful individuals. For example, a top-selling salesperson might be asked to work the company exhibit booth at a Las Vegas, San Francisco or Los Angeles trade show. The expectation was that while one would work the booth during the day, one could enjoy the delights of a new city at night. To some it was simply a paid holiday. To most, a trade show was something that required no preparation or training aside from showing up. As a result, companies tended to participate in shows without setting performance metrics. Even when they did, they were the wrong metrics. One common example involves measuring the number of brochures delivered at a show. Exhibitors usually cite industry assumptions that some percentage $-20,25$ or 30 percent - of all brochures are read. In fact, handing out printed material is about as effective promotionally as direct mail might be. Typically, attendees stuff the material into one of the ubiquitous free ad-imprinted bags that are distributed at every show. There is no assurance that the receiver does more than exit the show area with the material. Even if the brochure does make it past the strategically placed trashcans by the exits, it may not make it out of town. Hotels are known to bring in dumpsters during events just to handle the overload of trashed materials. One of the authors researched how attendees handle trade show take-aways. Typically, they keep an imprinted cloth bag because it has obvious value. When they return to their offices, the bag often ends up on the floor in a corner; its contents unexamined. Sometimes several bags end up side by side, their contents similarly ignored. Thus the expensively produced four-color process, eight-page brochure, transported at additional expense and handed out by well-paid employees in a very expensive trade show booth is wasted.

Recent industry research by the Center for Exhibition Industry Research (CEIR) states that $60-85$ percent of all brochures are thrown away. Of the remaining percentages, many are never looked at again even though they go home with the attendee. This is additional support for the assertion that the actual number of read brochures is closer to the results of direct mail.

Since exhibit marketing is virtually ignored at business schools, few promotional managers have a theoretical background that can underpin their trade show efforts. 
Strategically, exhibit marketing practice lacks the structure that a strategy conveys and thus tends to waste resources. Over 70 percent of exhibitors have no plan for their event participation, short of, "we need to support the industry", or, "we want to make sales", both vague goals at best. All the elements of corporate marketing are present in an exhibit marketing plan, albeit in miniature, so a plan needs to be created and implemented. Success is then more likely when companies have a well thought out marketing and promotional strategy.

\section{Evolution of trade shows as a strategic tool}

Early on, trade show potential was not well understood. It was clear that "writing business" was not an easily reached objective. Many companies exhibited at national trade shows because others in their industry did. As a result, many exhibitors simply participated without having a clear strategy and specific promotional objectives.

In the 1980s, when the US economy suffered several shocks, attendance at trade shows decreased. That reflected a concern for corporate finances that dispensed with activities judged not to be valuable. Those companies which found shows worthwhile continued attending. While decreasing attendance at events usually signifies challenges, in this case it meant that attendees were of "higher quality", often decision makers. In the prospect selection sense, the attendees who continued to attend trade shows were those who were attractive to exhibitors. The concentration effect was analogous to the narrowcasting trend in broadcast media. In essence there was a higher concentration of excellent prospects at the shows and a higher need to compete for them.

As the global economy suffers downturns and changes like the increasing competition from emerging markets, exhibit marketing should be reexamined. This paper examines the strengths and benefits of event marketing and offers a new view relating it within the integrated marketing framework.

\section{Exploiting the power of exhibit marketing}

Exhibit marketing is the most cost-effective means of reaching customers and prospects. It reduces the buying cycle and it allows companies to reach hidden buyers. One industry pundit called a trade show a four-day "bricks and mortar retail store" where customers could enter, learn about products and perhaps even buy. Most important, though, is that it can reduce the cost of a sale by as much as 75 percent (Weisgal, 1999). In essence, exhibit marketing is nothing more than marketing in miniature. Every facet of a businessmarketing plan is present in an exhibit marketing program. The only difference is the scale: the plan is smaller, shorter and takes place within a finite period of time.

In a recent survey, trade shows proved to be the primary source of purchasing information, beating out traditional elements such as advertisements and articles in trade journals, manufacturer's representatives, catalogues, and even business associates. Industry figures show that, on the average, 70 percent of trade show attendees plan to buy one or more products offered by exhibitors. Moreover, 75 percent actually make a purchase. If these results were not impressive enough, a huge number - 93 percent - said the convention influenced their buying decision. Marketers know that that kind of response is the stuff of which dreams are made. If not dreams, at least the results make hot customer lists.

However, industry sources reveal an almost unbelievable figure: 83 percent of those prospects were not called on by a company representative within a one year period after a show (Weisgal, 1999). Equally unbelievable is that 80 percent of exhibitors do not follow up on their leads. The figures only prove that exhibit marketing can increase and improve a company's business substantially, if - and only if - it is done properly. Failure to do it right will waste marketing dollars.

Sadly, too many companies have fallen into the technology trap. Customers seeking support nowadays must find a corporate telephone number. Sometimes they start at a web site. If they are lucky enough to find a contact telephone number, there is usually a bewildering set of instructions to navigate. They are often shunted to the corporate web site again. The result is an increasing number of barriers between customers and the companies that serve them. In the name of cost savings, companies have insulated themselves from their most valuable resource: their customers. Instead of building relationships, we ask them to use technology. It is as if marketers have forgotten that people do business with those they like, trust and respect. That means connecting on a personal level, something only a face-to-face meeting can engender. A trade show can provide that meeting.

\section{A framework for strategic management of exhibit marketing}

Weisgal (1999) offered an extremely detailed model for managing the exhibit marketing process. The model is based on a firm foundation of ongoing research into the customer, competition, exhibit venues and exhibit shows. Overall, it provides a decision platform to consider when employing trade shows in a promotional campaign.

\section{Ongoing research}

The framework (Figure 1) can be simplified to five main components and is cyclical. The framework is based on a foundation of continuous research and is the basis for its intelligent use. This may sound obvious but it is remarkable how little companies know about their current customers and competitors.

Figure $1 \mathrm{~A}$ framework for strategic management of exhibit marketing

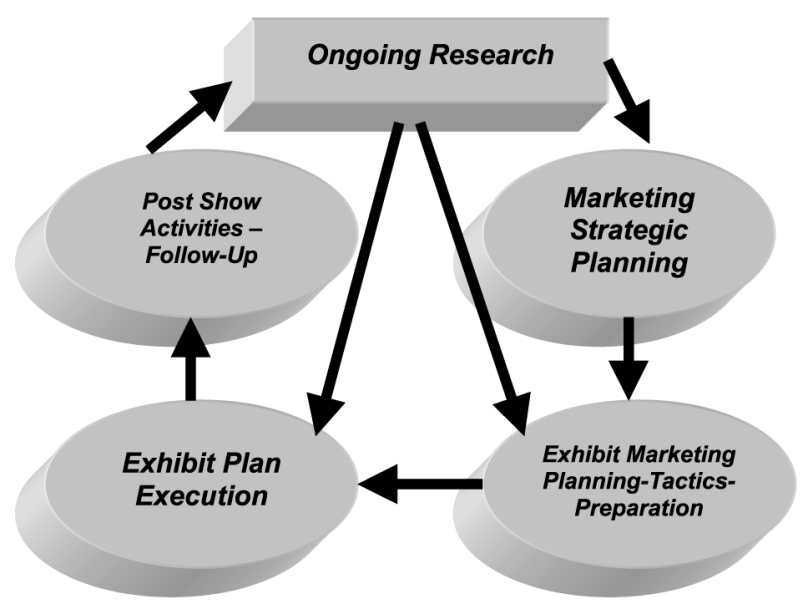


Although small companies are closer to their customers than multinationals, they are also less prepared to get to know their customers' needs, preferences, worries, challenges and lives. When a company targets a new market segment the lack of information can be staggering. Admittedly, the surface information is there, but information that can help develop a new product or promote an existing product to a specific client is not. An astute marketer listens with both ears and the very best ones get to know what their customers really want. We know the information source as demographic analysis. Knowing who your customers are, in what industry they compete, their main competitors and the factors that influence their success are important pieces of information. However, the descriptive information does not uncover exactly what a specific customer fears, desires or acts on. Professional marketers will go beyond simple descriptions and try to build a one-to-one relationship with a customer to understand his or her needs accurately.

The research process is not easy. At this stage of the process companies may not even know what questions to ask. It has been called the "fuzzy front end of consumer research". Further downstream in the research process, it is easier to identify the questions that will verify that companies are on the right track or those that will result in improvements to concepts that are already defined. The "how do you like it" and "how would you make it better" questions easily roll off the researcher's tongue. Moreover, companies are quite comfortable with how to deal with the answers. The problem is that those answers are often worthless. A perfectly drawn random sample of consumers may state with certainty that they plan to buy five of the "red ones" in the coming year. That kind of answer does not betray the conditions that effect the decision like having a job, reasonable food, housing and energy costs, remaining healthy and not learning about a substitute that seems better than the "red ones". Marketers who really know their customers should know not just which alternative a customer will select but the underlying reasons why.

That "fuzzy front end" tends to be much more ambiguous and messy than later stages of consumer research. Here organizations are often searching for good problems to solve. They are searching for new hunting grounds, new areas of business opportunity. The questions are not, "How do you like it?" but more "Will you tell me about yourself?" and, "May I spend a day simply watching what you do?" These questions may be easy to ask but respondents may not be willing to answer them. That information is critical though; understanding the consumer sets the stage for the rest of the process.

There is a caveat: be wary! When some companies consider how to divine customer preferences they may conclude, "We already know the answers." The caveat should prompt the response, "How do we know?" The research team could be asking the same questions in the same way almost guaranteeing that they would get the same answers. One safeguard is to assume that everything a research team knows is wrong. The solution would be to change the way that the team asks questions. If they traditionally use focus groups, other alternatives like surveys, phone interviews or "day in the life" research might be helpful.

Often companies collect information about consumers from their boundary spanning employees: the sales force. This source may be the only one available. However, organizations should be aware that while the information from the field could be valuable, it is probably anecdotal and not fully representative of customers. The danger is that accepting anecdotal information without question can lead to problems.

Figure 1 shows connections between ongoing research and multiple stages in the exhibit marketing process. These links emphasize the importance of continually updating plans and activities in the light of new information. The connections also imply the need for planned flexibility to adapt to changing situations.

\section{Marketing strategic planning}

Lessons taught by experience point out that in order to make exhibit marketing successful, one must have a plan. Actually, one must have several plans: a marketing plan and an exhibit marketing plan.

To support planning, ongoing research should focus on competitors, new developments in the field and the other research necessary to structure an overall marketing strategy. Thus, firms have to perform the typical strengths, weaknesses, opportunities and threats (SWOT) analysis. SWOT analysis looks closely within the company and outside into its environment and is a necessary condition for successful exhibit marketing. It was noted above that trade shows and personal selling comprise most of the promotional budget for small firms. Smaller firms are less likely to have a clearly articulated marketing strategy. They may have an idea of the markets, competitors and the direction they hope to take. That is no substitute for the detailed consideration of each aspect of a marketing plan that larger firms develop routinely.

Both marketing plans and their use have been featured in the academic literature extensively. There is no need to comment on each part of the typical detailed marketing plan. Marketers should use the basic framework: situation analysis, market summary (including a clear understanding of market needs, trend and growth), SWOT analysis (including a clear understanding of competition and the keys to success), marketing strategy (including a mission statement and objectives), implementation action plan and metrics, and finally contingency planning to chart a clear pathway to success. Organizations that have created, reviewed and tested a marketing plan have a great advantage over those who "know their marketing job" without having written and reviewed an entire plan. Industry figures point out a stark reality: a shocking 70 percent of exhibitors do not have an existing marketing plan on which to base their trade show efforts.

Lessons taught by experience point out that in order to make exhibit marketing successful, one must also have a specialized exhibit marketing plan that integrates with and complements the firm's marketing plan. The exhibit plan, like the marketing plan, requires objectives. In fact, making exhibit marketing successful means setting objectives, such as increasing brand awareness, product knowledge, or brand preference. The objectives may be generating qualified leads, gaining new distributors, gaining industry or competitive intelligence and enhancing customer relationships. Since the exhibit plan is not well covered in the marketing literature, it will be described in more detail than the familiar marketing plan. 


\section{Exhibit marketing planning, tactics, preparation}

Only 29 percent of firms that participate in trade shows have developed specific trade show objectives and, worse, only half of these actually follow through at the show (Dallmeyer, 1998). Given the overall lack of marketing plans among exhibitors, it is clear that most of them have not developed overall strategic objectives. At best the lack of a foundation provided by a marketing plan may reduce effectiveness; at worst, it can waste the promotional effort and tarnish the company's image.

It is true that attendees at a trade show are a select audience and are more valuable than a random group of consumers or business contacts. However, trade show exhibitors must interact effectively with show visitors. Effective interaction takes planning and effort and is less common than one would think. Industry experts stress the need for a proper exhibit marketing plan. Having both a strategic exhibit marketing and tactical plan of action is a critical starting point. Furthermore, it is important to have total alignment between the strategic marketing and your exhibit marketing plan. Otherwise, the trade show will be a stand-alone venture instead of a synergistic part of the organization's overall marketing operation (Naik and Raman, 2003). It is critical for an exhibiting company to know and understand exactly what it wishes to achieve. The objectives may follow the traditional product market matrix that all basic marketing courses include. Thus the objectives would be market penetration (increasing market share with existing users) product development (introducing new products/services into existing markets), market development (introducing existing products/services into new markets) and finally diversification (introducing new products/services into new markets).

Beyond introducing new or modified products, other trade show objectives include:

- identifying prospects;

- servicing current customers;

- enhancing corporate image;

- testing new products;

- improving corporate morale;

- gathering competitor information;

- selling at the show itself, and

- conducting customer research (Bonoma, 1983).

Building relationships with customers is another important objective. For simplicity, this list of activities was distilled into selling and non-selling functions based on a clinical study of trade show management practices.

For organizations that provide customized, complicated or expensive products, the non-selling objectives are more critical and set the stage for the personal selling interaction. For these products and services, highly interactive personal selling is the appropriate method of gaining adoption. From the exhibitor's perspective, learning an attendee's needs, product line, important competitors and key contacts within the company provide invaluable assistance to the sales force. In turn, the attendee can learn about the exhibitor, its potential product solutions - and coordinate a meeting to solve its problems.

For companies with less expensive products, the non-selling objectives may still be important. High-end specialty advertising items that integrate into a custom promotional campaign will require further exhibitor-attendee interaction. On the other hand, exhibitors who provide inexpensive or standardized products may expect to sell significant amounts at a show and will set important sales objectives.

When exhibitors have a well-reasoned exhibit plan, they have a better chance of overcoming the inevitable piece of adversity. No matter what the exhibit objective is, wellprepared exhibitors will consider contingencies and have the advantage of reflection that may help them cope with difficulties. As an example, an industry leader reports snatching success from disaster at an important industry show. Her lavishly prepared, elegant and expensive display booth never arrived at the venue. Neither did the promotional material that was clear and effective. What could be done? Having an exhibit plan presented some alternatives. One objective was to qualify prospects and assemble a list of their contact information. She visited a mall, bought an elegant silver bowl, some display boards and markers, and printed up lead forms. She prepared a sign that read, "My exhibit is stuck in Duluth. Please leave your card and I'll send you one of the nice presents I planned to give out." Attendees sympathized with her predicament and her humor in the face of adversity. The result was a useful list of leads she contacted effectively after the show.

\section{Attracting platinum attendees}

As the exhibit plan takes shape, planners should consider what tasks must be performed before the trade show. One challenge is to attract the right kind of attendees to the booth. Major shows with thousands of exhibitors create a recognition nightmare. Techniques such as searchlights in the sky and blimps flying overhead will not work in an auditorium. That is not quite true. Exhibitors have used them but they are not selective attention attractors. Other attention attracting methods will work at a show. The key issue is not attracting attendees in general but a niche audience, those with the highest profit potential. Marketers who are familiar with the customer value pyramid literature rank their customers ranging from platinum to lead based on their lifetime value (Zeithaml et al., 2001). One platinum customer is worth "tons" of lead customers. The marketing plan probably identifies the platinum group. The exhibit plan should have a way of attracting them to the booth. Armed with an attendee list provided by trade show management, the exhibitor can prepare a targeted booth visit campaign. One award-winning example in the promotional products industry involved targeting 250 of the most important prospects who planned to attend a major industry show. Each one was sent an expensive and elegant leather bound portfolio with a debossed area on the front cover and, inside, a special invitation from the president of the company to visit the booth. A custom nameplate, designed to fit in the debossed area and engraved with the invitee's name, would be waiting at the booth. A total of 63 percent - a huge 187 recipients, navigated their way to the booth. The response was so overwhelming that industry sources continue to cite the technique as an effective use of speciality advertising. After the event, company salespeople called those who had not picked up their nameplates and got a warm welcome when they dropped by. In this case, the exhibitor used a highly selective targeted direct mail campaign. Direct mail may be used more generally and sent to a larger sample than the select 250 mentioned above. It is a useful way to attract attendees to a specific exhibit as 
52 percent say that direct mail is the reason they visited the booth (CEIR, 2000).

Industry practitioners know the value of carefully considering details about specific trade shows. They endorse the value of ongoing research and emphasize that it is needed when planning for both new and familiar exhibits. As noted above, there are thousands of trade shows and scores of shows specific to an industry and there are guidelines for maximizing promotional success. There is no substitute for attending the show as a visitor the year before a planned exhibit to verify that the venue and the attending target audience will be appropriate. The time involved can be a day or less and the expense will be much lower than that an unproductive exhibit would incur. Alternatively, one might contact a close customer and ask which shows he or she attends. That information might help weed out the less valuable events. Experienced event planners look closely at previous years' exhibitors. They look for their competitors, a positive sign that the show is valuable. There might even be some exhibitors who are in the same industry, but are not competitors, who might provide additional information.

There are other nuts and bolts factors to consider with unfamiliar shows. Advertising media set their rates based on their viewership or readership. Trade shows follow a similar practice. Unlike advertising media, which have audited circulation figures, not all trade shows have audited attendance figures. The exhibit research should determine whether the show breaks out, with separate figures, attendees and exhibitors. Some shows lump everyone together. One show producer counts visitors every time they come through the door; three days produces three times the actual number of attendees. Exhibitors who accept such figures are wasting money.

Geography may be important when considering where the show is taking place in relation to an exhibitor's market. If the company is national, the show should draw a national audience. The show's management plays an important role in promoting attendance. It may advertise in trade papers, use direct mail, and offer prizes and inducements to get prospects in the door. Research can help evaluate the attractiveness of exhibit venues.

Research should not be limited to new or unfamiliar trade shows. Experienced exhibitors must re-evaluate their current commitments to maximize their effect. It is seductive for firms that have had successful shows to add more to their schedule. Planners should examine their show schedule carefully to insure that it is optimal. Perhaps fewer shows would achieve objectives just as well. Alternatively, perhaps the space at shows should be reexamined and adjusted.

Exhibitors know that reaching the right market segment is a key to success. Show management can usually provide a breakdown of attendees' job titles, which can then aid in evaluating the quality of the attendees. From the titles, planners can determine if the audience is comprised of decision makers or not.

\section{Metrics, training and rehearsing}

Metrics, the critical benchmarks of achievement, must be determined rationally. They will form the basis of post show evaluation and must reflect the objectives of the marketing and exhibit plan.
One major criticism of exhibit marketing researchers is that the level of "boothmanship" at a show is uneven. In some exhibits, personnel are well trained, balancing discretion and an outgoing approach. They know the exhibit plan objectives and what their company will value and reward. Usually, these exhibitors come away with their objectives met. If an objective is customer research, the personnel will gain the information effectively without acting like inquisitors.

Unfortunately, a majority of exhibitors fail. The reasons vary and may result from not having an effective marketing or exhibit plan with measurable objectives. Possibly they have not trained their personnel formally and not emphasized whatever show objectives were set. The symptoms of poor preparation are many, often reflecting the need to understand the similarity to retail sales. In some cases, booth personnel talk to each other and fail to pay sufficient attention to attendees. Alternatively, they may be clumsy or inappropriate in action. The personnel who concentrate on saying hello and handing out brochures or asking, "May I help you?" are too common and waste an excellent promotional opportunity. Usually a formal training program will reduce these problems and allow an exhibitor to get the most out of the effort.

The custom engraved nameplate promotion mentioned above was masterfully handled before and during the trade show. Personnel were trained on the best way to handle the group of highly important decision makers. Not a single member of the booth staff just found and handed over a nameplate. The booth staff included successful sales personnel and support staff. When a target visitor arrived at the booth he or she was greeted by a salesperson. If the target visitor asked for his or her nameplate, the salesperson would ask a support staff person to find the name plate for $\mathrm{Mr}$ or $\mathrm{Ms}$ Visitor. The nameplates were arranged in a box alphabetically and could be retrieved in moments, but because of good preparation, each search always took four to six minutes. During that time the salesperson would skillfully probe for information and custom tailor his or her response to the customer's interests. By the time the nameplate appeared, the exhibitor knew much about the prospect and, if the visitor was a qualified prospect, usually arranged a follow-up visit. Moreover, at the end of the visit, salespeople invited each target visitor to a courtesy event to continue relationship building.

\section{Exhibit plan execution}

Exhibit plan execution is so highly dependent on planning and attention to detail that is it a bit difficult to separate the stages. The activities in this stage will be successful if the exhibitor is successful in planning and preparation. It is almost enough to put managerial controls in place to handle exceptions and problems. However, execution deserves some detail.

A recent study examined exhibit staff performance. The authors classified the attending audience into three categories:

(1) Aggressive - people who were really interested in the product or service and came into the booth, across the invisible divider between the aisle carpet and the exhibit space, eager and ready.

(2) Curious - those who stayed at the edge of the carpet but evinced interest.

(3) Passive - aisle walkers who sort of stopped and looked. 
Their expectations were that staff would be able to "close" operationalized as to interact with and qualify the aggressives to a higher extent than the other groups. Results were startling: the exhibit staff closed passive visitors at the same rate as aggressive visitors. The results showed that the staff really did not engage the aggressive visitors, people who were really, truly interested at all (CEIR, 2003).

The authors attributed the effect to using internal training personnel with little perceived authority. In fact, internal training resulted in lower results than none at all. Outside experts were perceived differently and as more effective. The act of formal training is highly important since it creates a team that understands and accepts the company's reasons for exhibiting. Without guidance and direction, staff people sometimes decide for themselves what they should be doing at the show without regard to company expectations. The end result is a more consistent presentation by everyone at the show and no surprises.

To insure that the staff contributes during execution, numerous procedural items have to be accomplished. They range from setting a duty roster and shift schedule to booth attire. Experts even advise asking for shirt sizes if the attire will be company uniforms created for the show. To avoid mixups, personnel should know general show data such as hours, days, and set-up times; show goals/objectives; and pre-/ at-show promotions.

The most effective staff will know the situations for which the company has a product or service solution. It is also necessary to have staff perform or review competitive analysis assignments to prepare themselves with relevant competitive information. Some successful exhibitors set up a booth layout and walk their staff through it to practice and familiarize them with the layout, where things are stored, and demonstration areas. If an objective is generating leads, experienced exhibitors train staff how to gain information necessary to complete lead forms.

Perhaps the most important execution behavior is for the staff to learn to listen first and present second. An excellent dialogue in a booth consists of learning first what brought the visitor in, why s/he is there, and his/her needs or objectives for the product or service. Furthermore, staff must learn if the visitor is a decision maker, influencer, specifier or initiator. Getting answers to these questions at the beginning is critical. Armed with the information, the staff person will be prepared to tailor a promotional response to be relevant to the visitor. One trainer states that letting people talk and actually listening to the responses fulfills an innate need to be valued. People love to talk about themselves and a skilled marketer can elicit information of commercial value. Staff should use a prepared and tested in-booth dialogue. The objective is to learn at the same time as selling and informing. The idea is to decide what is important to know both to qualify potential customers and learn enough to make a sensible proposal. Opening questions might include geographic location, job title and functions, applications needed, market served and future plans. Questions should be open ended to elicit clear information and keep the person talking.

At this stage, exhibitors can confirm the status of visitors on the platinum to lead continuum. The questions that qualify prospects should be used at the start of the conversation to decide whether to go on or close out the contact quickly. Too often, booth staffers spend time with people who do not have a need for company products or services - the lead customers. The objective is to identify and spend considerable time with the platinum prospects.

The best execution concentrates on the benefits or applications of exhibitor products to the visitor. The old adage that people buy what something does for them, the product is what gets them there, is true. Skillful sales people practice blending benefit/application statements with the open-ended questions that solicit information. They usually make a statement followed by the next question. With practice, the sequence will become easier and more effective.

Perhaps the most important part of execution is the closing. If there is a sales objective this translates into asking for the sale. If the objectives are non-sales oriented the questions will be different. There are guidelines to ask for an expression of interest within five minutes. The objective is to get an agreement: "What is the next step, after the show, that you would like see happen?" or "What would you like me to do next?" or "Where do we go from here?"

\section{Post-show activities}

Without some form of tracking system in place, it is impossible to know whether or not the show benefited the company. Trade shows do not end until the follow-up is done. There is an adage about follow-up: "You are only as good as your last contact". So if a company makes a promise or a commitment at a show - and never does anything credibility is destroyed. One problem noted above is the lack of follow up on leads. If the leads are properly selected and qualified, they are valuable and should be treated as such. Marketers need to safeguard the collection of leads generated at a show. Sometimes they are placed in the packing case with the booth, never to be found again. The proper treatment is to review them each evening and make additional notes before finishing the day's work.

Back in the planning stage, experienced exhibitors create customized lead forms and train staff to use them. The expense involved in doing this is insignificant - as most can be done easily with any computer word processing program and their value is indisputable. In addition, this lead form acts as a guide to asking the correct questions before doing a presentation. It is also a reminder for those who work the booth to listen first, and then position the response in terms that relate to the prospect or customer. The forms provide a systematized way to trap the information collected at the show, one that details information rather than relies on a scrap of paper. Ineffective staff take a business card, make a few scribbled notes on the back and then stick the card in their pocket. This is a recipe for losing the information and the business it might bring.

Creating a lead form is simplicity itself. The difficulty lies in determining beforehand what information is necessary for productive follow up. Certain requisites are elementary to every version - such as name, company, title, address and other contact information. A business card can be collected and attached, or the form can be completed by hand. Business cards ensure that the data are accurate. No one ever lets a business card out of his or her hand without it being exact, even if the owner handwrites new data on it. Numerous contacts supply cards with a line scratched out and updated information written in.

The most important post-show activity is actually doing something. Records should capture what was actually done 
for the customer. For instance, on what date was the information sent? Alternatively, when was the telephone call made? Was an appointment scheduled? What resulted? To repeat, a company is only as good as its last contact. The more it seems to care about its customers, the more they will care about the company. When all is said and done, industry figures state that only about 20 percent of a contact goal should produce a qualified lead. Of those, half should close within 12 months following the event. If results are different, it might warrant taking a new look at the show. There are, of course, anomalies; for instance a company with an average sale of several million dollars will not collect new leads amounting to 20 percent. But then again, that should not be its objective. It should aim towards maintaining contact and moving the sale forward by solidifying the relationship with the prospect or customer.

Some guidelines for measuring results are:

- have a procedure for reporting back to management;

- compare results to objectives; and

- re-evaluate your show participation.

\section{Summary}

Exhibit marketing has been misunderstood in the past. Newer perspectives see its value as a vital part of the IMC process. To be successful, exhibit marketing must be firmly integrated within the IMC process and the company's marketing strategy. It requires its own mini-marketing strategy: the exhibit marketing plan. Moreover, the exhibit plan objectives must integrate well with marketing plan objectives. Industry results show that successful exhibit marketers treat the activity seriously devoting much planning, training and processing time to the show. Finally, follow-up is a key differentiator between successful exhibitors and those who are not.

As exhibit marketing continues to become more important in the IMC process, experienced exhibitors who act professionally will gain an advantage over those who take a more informal approach.

\section{Implications for marketers}

Marketers should give exhibit marketing its proper place in IMC. The consumer relationship building and ordergenerating benefits of exhibit marketing are too valuable to waste. Exhibit marketing may not be the right tool for every promotional situation. However, it works in B2B and business to customer (B2C) applications and delivers an excellent number of qualified prospects. In some cases, organizations should consider reorganizing the marketing communications function to reap the benefits of trade shows.

To exploit the potential of trade shows, exhibit marketing needs its own strategy complete with measurable strategic goals. Those goals and objectives should stem from a wellconsidered dialog within the company. All of the participants from the stock room clerks assembling promotional material to the logistics manager who is responsible for insuring that displays and material get to an exhibit should know what is important and how to do it. Personnel detailed to work the trade show must be well trained and know the objectives they need to attain. Communication here is critical. Companies with bureaucratic standard operating procedures may find a conflict in what a trade show demands and how a company normally handles things. The exhibit plan must be specific enough to avoid misunderstandings.

As with any strategic exercise, exhibit marketing needs a strategic budget and reward structure to insure that its goals are met. Everyone connected with a company's exhibits should have a rooting interest in success. Thus rewards for successful contributions and sanctions for failure should be part of the process. Similarly, a strategic plan will determine the level of funds needed for achieving success.

Some of the examples highlight the need for creative responses to trade show challenges. Creative skills may be widespread throughout the company. If marketers can energize their personnel with information, challenges and the prospects of rewards they may increase the quality of its exhibit marketing.

\section{References}

Barker, J. (2005), "Show time", Sales \& Marketing Management, Vol. 157 No. 6, June.

Bonoma, T.V. (1983), "Get more out of your trade shows", Harvard Business Review, Vol. 61, January-February, pp. 75-83.

Center for Exhibition Industry Research (CEIR) (2000), Staggering Stats Substantiate Exhibition Participation, CEIR, Chicago, IL, p. 11.

Center for Exhibition Industry Research (CEIR) (2003), The Role and Value of Face-to-Face Interaction, CEIR, Chicago, IL.

Chapman, E.A. (1995), Exhibit Marketing, 2nd ed., McGrawHill, Maidenhead.

Dallmeyer, R. (1998), Cold Facts. Hot Tips, Center for Exhibition Industry Research, Chicago, IL, p. 4.

Gould, S.J. (2000), "The state of IMC research and applications", fournal of Advertising Research, SeptemberOctober, pp. 22-3.

Kerin, R. and Cron, W. (1987), "Assessing trade show functions and performance: an exploratory study", fournal of Marketing, Vol. 51 No. 3, pp. 87-94.

McCarthy, E. (2005), The Washington Post, November 28, p. D15.

Naik, P.A. and Raman, K. (2003), "Understanding the impact of synergy in multimedia communications", fournal of Marketing Research, Vol. 40 No. 4, pp. 375-89.

Schultz, D.E. (1993), "Integrated marketing communications: maybe definition is in the point of view", Marketing News, Vol. 27 No. 2, p. 17.

Shenk, D. (1997), Data Smog: Surviving the Information Age, Harper, San Francisco, CA.

Spethmann, B. (2005), "Buzz gets louder", Promo, April 1.

Weisgal, M. (1997), Show and Sell, 133 Business Building Ways to Promote Your Trade Show Exhibit, AMACOM, New York, NY.

Weisgal, M. (1999), 12 Steps to Exhibit Success, Prosemics Press.

Zeithaml, V.A., Rust, R.T. and Lemon, K. (2001), "The customer pyramid: creating and serving profitable customers", California Management Review, Vol. 43 No. 4, pp. 118-34. 


\section{Further reading}

Friedman, S.A. (2001), "Avoid the top 10 errors of trade show exhibits", TWICE: This Week in Consumer Electronics, Vol. 16 No. 1, January 6.

Friedman, S.A. (2002), "Ten steps to a successful trade show", Marketing Health Services, Vol. 22 No. I, Spring, pp. 31-2.

Trade Show Bureau (1983), The Exhibitor: Their Trade Show Practices, Study No. 19, Trade Show Bureau, East Orleans, MA.

\section{About the authors}

Dennis A. Pitta, PhD is Professor at the Merrick School of Business, University of Baltimore. $\mathrm{He}$ is a distinguished teaching professor and has authored numerous articles in product management and healthcare marketing. His current research interests are new product development, and the effect of new technologies on marketing.

Margit Weisgal is a gifted teacher and author having authored over 20 books dealing with practical marketing topics in promotion and marketing practice. She is the president of Sextant Communications, a multi-service promotional agency and an Assistant Professor of Marketing at the University of Baltimore.

Peter Lynagh, PhD is the Frank W. Baker Distinguished Professor at the Merrick School of Business, University of Baltimore. He is an award-winning teacher and has authored numerous articles in advertising, marketing communications and logistics.

\section{Executive summary and implications for managers and executives}

This summary has been provided to allow managers and executives a rapid appreciation of the content of this article. Those with a particular interest in the topic covered may then read the article in toto to take advantage of the more comprehensive description of the research undertaken and its results.

Marketing at trade shows and other events has been an underused strategy in recent decades. In the USA, the decline began in the 1980s, when economic uncertainty prompted many organizations to cut back on expenditure that was deemed unnecessary. However, there are signs that the popularity of exhibit marketing (EM) is on the increase. In 1995, for example, companies spent 16-20 percent of marketing budgets on trade shows. Evidence suggests that, by 2004 , the percentage had risen above this level in the healthcare, financial and high-tech industries. It is now estimated that over 9,000 industrial, scientific and medical exhibits are held in the USA each year.

\section{Some benefits of exhibit marketing}

Pitta et al. claim that EM can play a key role within integrated marketing strategies that also include other techniques such as advertising, sales promotions and personal selling. Trade shows can help directly target a specific audience and offers cost effective marketing for small companies operating with limited budgets. This is important in an age where technology has introduced the likes of caller ID systems and a wealth of digital channels, making it easier for consumers to avoid techniques such as telemarketing and advertising. Trade shows have proven to be effective for both business-tobusiness (B2B) and business-to-consumer (B2C) purposes, not least because of the shared commercial purpose of those who attend.

Research has indicated that EM allows swifter contact between organization and customer and has the potential to reduce the cost of a sale by up to 75 percent. The authors also point out that 70 percent of those attending a trade show intend to make at least one purchase. The vast majority admitted that attendance considerably influenced their purchase decisions. The scope for success would be even higher if companies appropriately followed up sales or leads, but many have failed to do so. Such firms place the onus on the customer to initiate contact after the event, at least initially through the company web site. The failure to appreciate the importance of building personal relationships with customers is pointed out by the authors.

Part of the reason for such a slipshod attitude towards trade shows is explained by the absence of EM from many business school curriculums. This may also clarify why many firms' participation in trade shows has been characterized by a lack of strategy and performance measures.

\section{Why strategies are important}

The authors suggest that companies will only achieve desired results by learning about their customers and getting to know what they really want. This is particularly important when targeting new market segments, where there will invariably be a need to go beyond generally available information to find out what makes the customer tick.

Doing this homework should be part of a strategic plan that provides the foundations for EM and other marketing elements. Ongoing research is an integral part of the plan if the organization is to gain insight into competitor plans and new developments in the field. And in addition to enabling companies to become aware of their own particular strengths and weaknesses, thoroughness of research will serve for flexibility and swifter response to unanticipated developments. Despite the obvious importance of marketing plans, figures show that more than 70 percent of exhibitors do not have any current strategies to base their trade show on.

The importance of developing specific plans for EM itself is pointed out by Pitta et al. Indeed, not doing so can leave a company reeling from lost potential, wasted resources and even a stained image. A specialized marketing plan will enable a clearer focus on objectives that might include increasing brand awareness, boosting corporate image or acquiring knowledge about competitors, in addition to gaining sales at the show itself. Non-selling objectives will be even more important to companies providing a more exclusive service. It is also crucial that EM aligns closely with overall marketing strategies to maximize impact. On the contrary, an event treated in isolation will be much less effective.

Companies shrewd enough to do their homework will also appreciate the need to attract the right type of attendees to the event. Quality rather than quantity will invariably prove to be the key here. To this end, the exhibit plan should include strategies to identify and target the clientele most likely to commit to purchase. It is more than useful to discover attendees' job titles in order to ascertain the decision makers among those present. During the event itself, those involved 
in running the stand should be able to discriminate between casual observers and seriously interested attendees likely to offer greater profit potential. Of course, such people must be there in the first place, so it pays to carry out necessary checks beforehand. The presence of competitors is also usually a good sign. Wise organizations will also choose to exhibit at events held at geographically suitable locations and will advertise their presence using effective channels.

Success is likelier if company personnel working at the event are trained properly beforehand. Appropriate training will enhance preparations, sharpen the focus, improve communication, and clarify individual roles and show objectives. Another consequence will be having employees who are more knowledgeable about the company and its products. It can be a useful strategy to link rewards and sanctions to event outcomes.

The wise organization will realize that the event is only the start and that follow up commitment is vital if opportunities are to be capitalized upon. Formal record keeping at the show is therefore a must, while also sending out the right signals about the company's professionalism. Perhaps even more importantly, customers may feel the company that bothers to make subsequent contact is one that actually cares about them.

(A précis of the article "Integrating exhibit marketing into integrated marketing communications". Supplied by Marketing Consultants for Emerald.) 